\title{
The Impact of Covid-19 in the Follow-Up of Glaucoma Patients in a Tertiary Center: A Comparison Between Pre-Pandemic and Pandemic Periods
}

\author{
Gabriel Ayub \\ José Paulo Cabral de \\ Vasconcelos \\ Vital Paulino Costa \\ Department of Ophthalmology, \\ University of Campinas, Campinas, São \\ Paulo, Brazil
}

Purpose: To evaluate the impact of Covid-19 on the treatment and follow-up of glaucoma patients in a tertiary center.

Materials and Methods: We compared the total number of outpatient clinical visits, visual field exams, surgical procedures and medications released in the pre-pandemic period (March 2019-February 2020) and pandemic period (March 2020-February 2021). We also performed a paired analysis, which included patients who were examined in both periods, comparing the number of visits and medications.

Results: The total number of outpatients clinical visits, visual field exams, surgical procedures and medications released decreased $92.52 \%$ (7117 vs 532), 93.84\% (1525 vs 94), $72.74 \%$ (682 vs $145)$ and $19.63 \%(23,259$ vs 18,692), respectively, when the pre-pandemic and pandemic periods were compared. The mean number of annual clinical visits per patient $(1.8 \pm 0.79 \mathrm{vs} 1.04 \pm 0.18$, $\mathrm{p}<0.0001)$ and surgical procedures per patient $(1.46 \pm 0.92$ vs $1.13 \pm 0.41, \mathrm{p}<0.0001)$ decreased significantly, whereas the mean number of medications released per patient did not change significantly $(28.62 \pm 19.11$ vs $30.34 \pm 20.15$, $\mathrm{p}=0.97)$. In the paired analysis, the mean number of visits ( $\mathrm{n}=423$ patients) decreased from $1.86 \pm 0.76$ to $1.04 \pm 0.19(\mathrm{p}<0.0001)$ and the mean number of medications ( $n=561$ patients) decreased from $33.44 \pm 18.61$ to $31.97 \pm 19.86$ in the pre-pandemic and pandemic periods, respectively $(\mathrm{p}=0.393)$.

Conclusion: The Covid-19 pandemic dramatically decreased the number of outpatient visits and surgical procedures, impacting the follow-up of glaucoma patients in our service. We encourage other health care units to verify the impact of the pandemic in their own population to better prepare for a possible overload of uncontrolled glaucoma patients in the future.

Keywords: glaucoma, Covid-19, SARS-CoV-2, pandemic

\section{Introduction}

Glaucoma is the leading cause of irreversible blindness in the world, affecting over 76 million people in 2020 and 40 million more in the years to come. ${ }^{1,2}$ In Brazil, it is estimated that $3.1 \%$ of the population over the age of 40 is affected by the disease, ${ }^{3}$ which represents over 6 million people. The diagnosis and treatment of glaucoma patients are both fully covered by the country's public health system (SUS).

Since November 2019, a series of pneumonia cases with unidentified cause were reported in China, ${ }^{4}$ which alerted health authorities for a new emerging health issue.
Correspondence: Gabriel Ayub Department of Ophthalmology, University of Campinas, 25I Vital Brazil St., Campinas, SP, I3083-888, Brazil, $\mathrm{Tel} / \mathrm{Fax}+55$ (19) 352I-7337

Email gabriel.ayub@gmail.com 
The agent was later identified as a coronavirus, named Covid-19., 5 The virus spread worldwide, and the World Health Organization (WHO) declared it a pandemic in March 2020. ${ }^{7}$ Since then, the world registered almost 240 million cases and 5 million deaths. Brazil's first confirmed case was registered on February $26,{ }^{8}$ and the virus spread widely across all regions of the country. ${ }^{9}$ Now, Brazil has reported 21 million Covid-19 cases and over 600 thousand deaths. ${ }^{8,10}$

In an attempt to reduce patient exposition to Covid-19, ophthalmological societies worldwide released, short after the declaration of pandemic by the WHO, recommendations for best practices in ophthalmology. ${ }^{11-13}$ Regarding glaucoma, the Royal College of Ophthalmologists released recommendations for urgent and elective surgeries, and for the follow-up of patients with ocular hypertension and glaucoma. ${ }^{14}$

Covid-19 outbreak forced countries to focus most of the efforts on emergency units in order to treat the high number of cases in a short period of time, given the quick spread of the virus. This forced several other health services to suspend activities, which left a high amount of chronic patients without medical assistance. Some studies verified the impact of lockdown on ophthalmology assistance ${ }^{15}$ and resident training, ${ }^{16-18}$ while others investigated the impact on glaucoma practice and patients' assistance. ${ }^{19,20}$ However, to the best of our knowledge, none of these studies verified the impact of the pandemic on glaucoma patients followed at a large public glaucoma service. This would help to understand the impact on patients' assistance and prepare health services to better perform when the pandemic is resolved.

The aim of this study was to evaluate the impact of Covid-19 on the treatment of glaucoma patients followed in a tertiary center, comparing the number of outpatient visits, visual field exams, surgeries and medications released before and during the pandemic.

\section{Materials and Methods}

This single-center retrospective cohort study was approved by the Ethics Committee of the University of Campinas (IRB \#45206221.5.0000.5404) and conducted in compliance with the Declaration of Helsinki. Informed consensus was waived by the Ethics Committee due to the retrospective design of the study.

All data were obtained from the electronic records of the Hospital das Clínicas da Faculdade de Ciências Médicas da Unicamp, which provides public tertiary health care as part of SUS. Our Hospital is reference for 42 municipalities, providing health services for an estimated population of 3.2 million people. ${ }^{21}$ The glaucoma service of the Department of Ophthalmology is responsible for all clinical visits and visual field exams; the ambulatory surgical center, for all surgical procedures; and the Hospital's Pharmacy, for medication release.

Data were acquired in May 2021 and divided into two intervals: from March 1, 2019 to February 28, 2020 (prepandemic group), and from March 1, 2020 to February 28, 2021 (pandemic group). This division was made based on the first case of Covid-19 detected in Brazil, which was confirmed on February 26, 2020. ${ }^{8}$

For the outpatient clinical visits and visual field analyses, only patients who attended the appointments were included. We looked for the total number of patients seen during each interval and the total number of visits done by each patient. All appointments were suspended since March 2020, and only emergency attendance was allowed during the pandemic period.

For the surgical procedure analysis, all surgeries performed by the glaucoma team of our institution (fellows, residents and staff) were included: trabeculectomies and tube shunts were clustered in the filtering surgery group; trabeculectomy or tube shunt associated with phacoemulsification belonged to the combined surgery group, whereas cyclodestructive procedures, phacoemulsifications, conjunctival sutures and needlings were analyzed individually. We calculated the total number of procedures performed in each period and the mean number of procedures done in each patient. Elective surgeries were suspended since March 2020, and only emergency procedures were allowed during the pandemic period.

We also calculated the number of medications released during each period (timolol maleate, brinzolamide, dorzolamide, brimonidine tartrate, travoprost, bimatoprost and latanoprost). The Hospital's Pharmacy does not release fixed combinations due to their higher cost.

A paired analysis, which included only patients who were examined in both periods was also performed comparing the number of clinical visits and medications released for each patient.

\section{Statistical Analysis}

The total number of patients, visits, surgeries and medications released are presented as descriptive data. Normality was assessed by the Shapiro-Wilk test. The non-paired Student's $t$-test was used to compare the continuous 
variables between the groups. Data from patients who attended both periods were analyzed with the Wilcoxon rank sum test. A p-value $<0.05$ was considered statistically significant. All the analyses were performed with the Statistical Package for Social Sciences - SPSS (IBM Corporation, Armon NY, USA, version 22.0).

\section{Results}

A total of 7117 clinical visits (3965 patients), 1525 visual field exams (1410 patients), 682 glaucoma surgical procedures (466 patients) and 23,259 medications released (813 patients) were observed during the pre-pandemic period, whereas 532 clinical visits (514 patients), 94 visual field exams (94 patients), 145 glaucoma surgical procedures (127 patients) and 18,692 medications released (616 patients) were observed during the one-year Covid-19 outbreak period. These findings represent a decrease of $92.52 \%, 93.84 \%, 72.74 \%$ and $19.63 \%$ in the total number of clinical visits, visual field exams, surgical procedures and medications released, respectively. Surgical procedure and medication details of each group are presented in Tables 1 and 2, respectively.

When we compared the pre-pandemic and pandemic periods, the mean number of clinical visits per patient reduced from $1.8 \pm 0.79$ to $1.04 \pm 0.18(\mathrm{p}<0.0001)$ and the mean number of surgical procedures per patient decreased from $1.46 \pm 0.92$ to $1.13 \pm 0.41(\mathrm{p}<0.0001)$, but the mean number of medications released per patient did not change significantly $(28.62 \pm 19.11$ vs $30.34 \pm 20.15$; $\mathrm{p}=0.97)$.

Among the 3965 and 514 patients who attended clinical visits during each period, a total of 423 attended both periods, which means that 91 new patients were seen in the pandemic period. The mean number of visits per patient in this group was $1.86 \pm 0.76$ in the prepandemic period and $1.04 \pm 0.19$ during the pandemic period $(\mathrm{p}<0.0001)$. Among the 813 and 616 patients who obtained medications in each period, a total of 561 received medications in both periods, which means that 55 new patients received medications at the institution, and 252 did not show up for medication release. The mean number of medications received per patient was $33.44 \pm 18.61$ vs $31.97 \pm 19.86(\mathrm{p}=0.393)$ in the prepandemic and pandemic periods, respectively (Table 3 ).

\section{Discussion}

Our study showed a significant impact of the Covid-19 pandemic on the care of glaucoma patients followed in a tertiary center. Significant reductions were identified in the number of clinical visits, visual field exams, surgical
Table I Surgical Procedures Performed in Each Period

\begin{tabular}{|l|c|c|c|}
\hline & $\begin{array}{c}\text { Pre- } \\
\text { Pandemic }\end{array}$ & Pandemic & Variation \\
\hline Combined surgeries & 189 & 12 & $-93.65 \% \%$ \\
\hline Filtering surgeries & 197 & 78 & $-60.0 \%$ \\
\hline $\begin{array}{l}\text { Cyclodestructive } \\
\text { procedures }\end{array}$ & 178 & 22 & $-87.64 \%$ \\
\hline Phacoemulsifications & 59 & 20 & $-66.1 \%$ \\
\hline Needlings & 54 & 8 & $-85.18 \%$ \\
\hline Conjunctival sutures & 4 & 4 & - \\
\hline $\begin{array}{l}\text { Total number of } \\
\text { procedures }\end{array}$ & 681 & 144 & $-72.74 \%$ \\
\hline Total number of patients & 466 & 127 & $-72.74 \%$ \\
\hline
\end{tabular}

Notes: Combined surgery $=$ phacoemulsification + filtering surgery, filtering surgery $=$ trabeculectomy or tube shunt.

Table 2 Medications Released in Each Period

\begin{tabular}{|l|c|c|c|}
\hline & $\begin{array}{c}\text { Pre- } \\
\text { Pandemic }\end{array}$ & Pandemic & Variation \\
\hline Timolol maleate & 5080 & 2655 & $-47.73 \%$ \\
\hline Brinzolamide & 4829 & 3734 & $-22.67 \%$ \\
\hline Dorzolamide & 2818 & 2850 & $+1.13 \%$ \\
\hline Brimonidine & 6467 & 5258 & $-18.69 \%$ \\
\hline Travoprost & 2985 & 3205 & $+7.37 \%$ \\
\hline Bimatoprost & 737 & 669 & $-9.22 \%$ \\
\hline Latanoprost & 343 & 321 & $-6.41 \%$ \\
\hline $\begin{array}{l}\text { Total number of } \\
\text { medications }\end{array}$ & 23,259 & 18,692 & $-19.63 \%$ \\
\hline Total number of patients & 813 & 616 & $-24.23 \%$ \\
\hline
\end{tabular}

procedures and medications released. To the best of our knowledge, this is the first study that investigated the impact of the Covid-19 pandemic on glaucoma care.

One year after the pandemic started in Brazil, despite efforts to limit the virus dissemination, ${ }^{22}$ the country failed to reduce its impact on the public health system, ${ }^{23}$ restricting the medical assistance for chronic patients. Our findings indicate a $92 \%$ decrease in the number of visits during the pandemic period. Among the 3965 and 514 patients who attended clinical visits during each period, a total of 423 attended both periods. Although we cannot guarantee 
Table 3 Paired Analysis of Patients Who Attended Both Periods (423 for Clinical Visits and 56I for Medication Release)

\begin{tabular}{|l|c|c|c|}
\hline & Pre-Pandemic Period & Pandemic Period & P-value \\
\hline Outpatient clinical visits & $1.86 \pm 0.76$ & $1.04 \pm 0.19$ & $<0.000 \mathrm{I}$ \\
Number of medications released & $33.44 \pm 18.6 \mathrm{I}$ & $31.97 \pm 19.86$ & 0.393 \\
\hline
\end{tabular}

Notes: Wilcoxon rank sum test was used to compare the variables. Statistically significant value is in bold.

that the remaining 3542 lost follow-up, we estimate that a large majority had a visit scheduled during the pandemic period and did not attend. Even patients attending both periods showed a substantial decrease in the mean number of visits per year, from $1.86 \pm 0.76$ to $1.04 \pm 0.19$, which represents a $44 \%$ reduction. Interestingly, the Brazilian Council of Medicine recently estimated a 34\% reduction in the number of appointments for retina and glaucoma between March and December 2020. ${ }^{24}$ Although we have not measured the real consequences of this reduction in glaucoma control, it is likely that the inadequate follow-up during this period has favored the occurrence of glaucoma progression, particularly in advanced glaucoma patients, who are more sensitive to undetected IOP variations. A previous study from our service ${ }^{25}$ reported that most of the patients on their first appointment at the glaucoma sector presented with advanced glaucomatous damage: $51.8 \%$ of them had unilateral visual loss and $33.3 \%$ had bilateral visual loss. Comparable findings were also reported by another Brazilian institution, where $42.03 \%$ of the patients already had unilateral visual loss by advanced glaucoma ${ }^{26}$ in their first appointment.

A recent study in India, ${ }^{20}$ a country that shares comparable socioeconomic issues and pandemic impact with Brazil, investigated patients' medication adherence and loss of follow-up during the country's lockdown. Among the 393 telephone-interviewed patients who had lost follow-up, $90.63 \%$ reported lockdown restrictions; $74.38 \%$, transportation problems; $9.09 \%$, absence of symptoms; and $4.13 \%$, financial difficulties as the reason to miss an appointment. Regarding medication adherence, $24.52 \%$ had stopped using eye drops for $1.78 \pm 1.34$ months, and $43.43 \%$ reported having missed the prescribed eye drops during the month prior to the interview. The major reasons cited for the non-adherence were non-availability of the drops $(54.81 \%)$, financial issues $(30.29 \%)$, no improvement with eye drops $(20.19 \%)$, other illness $(17.79 \%)$, unawareness of the importance of regular use (14.42\%) and unavailability of the caretaker $(10.10 \%)$.

Although telephone interviews have been employed to verify adherence, they are frequently susceptible to patients' overestimation of the treatment. ${ }^{27}$ We decided to verify medication adherence based on medication release ${ }^{25}$ by the Hospital's Pharmacy, which provides eye drops for a 3-month period with the same prescription. We have previously reported that $89.4 \%$ of our patients obtain their glaucoma medication at the Hospital's Pharmacy. ${ }^{28}$ A $24 \%$ reduction in the number of patients seeking the Hospital's Pharmacy to obtain medication can be explained by the loss of follow-up, or by difficulty in obtaining transportation, or due to a negative outcome during the pandemic. The first two reasons are associated with uncontrolled intraocular pressure (IOP) and possible glaucoma progression. ${ }^{29}$ In 2020 , due to social distancing and lockdown measures to prevent the virus spread, the Brazilian gross domestic product retracted $4.1 \%,{ }^{30}$ which is associated with a significant decrease in family income and increased dependence on social assistance and public services. In fact, $81 \%$ of patients were already dependent of SUS in our region even before the pandemic. ${ }^{31}$ Previous studies indicated that costs of glaucoma treatment with drops compromise $15.5 \%$ to $43 \%$ of the family income in Brazil. ${ }^{26,29-31}$ Hence, it is unlikely that patients who did not obtain their medication at our Hospital's Pharmacy could afford glaucoma medication on their own.

The number of glaucoma surgeries significantly decreased in our service. This can be explained by the fact that our Hospital suspended all elective surgeries in order to focus human and economic resources in the care of Covid-19 patients. ${ }^{23}$ Also, as recommended by different ophthalmology societies, ${ }^{12,14}$ we postponed non-urgent surgical interventions. A report from 39 academic ophthalmology centers in Italy, ${ }^{15}$ another country severely impacted by the pandemic, compared surgical interventions of the 2-month lockdown period (March 10 to May 9, 2020) to pre-lockdown months (January 10 to March 9, 2020) and corresponding 2 months of 2019 (March 10 to May 9, 2019). Overall, the number of surgeries decreased $68.8 \%$ and $69.9 \%$, respectively, with a reduction of $96.2 \%$ and $96.4 \%$ in the number of elective surgeries and $50.7 \%$ and $53.9 \%$ in the number of urgent surgeries. They also reported a decrease of $64.9 \%$ and $73.0 \%$ in the number of trabeculectomies, $40.5 \%$ and $58.9 \%$ in 
drainage implants, and $82.6 \%$ and $85.3 \%$ in cyclodestructive procedures when the 2-month lockdown period was compared to pre-lockdown months and corresponding 2 months of 2019, respectively. Furthermore, two reports from Poland investigating elective cataract surgeries ${ }^{32}$ and rhegmatogenous retinal detachment $^{33}$ found a decrease in the number of referrals and procedures. Considering the mean number of elective cataract performed between 2016 and 2019 as baseline, the number of procedures decreased $77.5 \%, 51.5 \%$ and $29.7 \%$ during the first (March/2020-May/2020), second (October/2020-December /2020) and third (March/2020-April/2020) Covid-19 waves in the country, respectively, with an average decrease of $53.4 \%$ during the pandemic. ${ }^{32}$ Similar findings were reported for retinal surgery referrals, with reductions of $48.4 \%, 18.5 \%$ and $26.5 \%$ during the first, second and third waves, respectively, with an average decrease of $16.5 \%$ during the pandemic. $^{33}$ These findings are comparable with those reported herein: a $60 \%$ decrease in the number of filtering procedures, $93.65 \%$ in combined procedures and $87.44 \%$ in cyclodestructive procedures, with an overall decrease of $72.74 \%$ in glaucoma surgeries.

Interestingly, the choices for glaucoma procedures have apparently been affected by the pandemic. In a study that involved 70 glaucoma specialists at the United Kingdom, ${ }^{19}$ $87 \%$ indicated trabeculectomy as their preferred procedure and $47 \%$ sub-Tenon's block without sedation as their preferred anesthesia in the pre-Covid period. In contrast, in the postCovid period, $61 \%$ reported changes in their surgical practice: $43 \%$ indicated a reduction in the number of trabeculectomies, which was substituted by micropulse cyclophotocoagulation (14\%), drainage devices (12\%), Preserflo, deep sclerectomy and continuous cyclophotocoagulation (7\% each); $72 \%$ reported no change in the preferred anesthesia, while $22 \%$ elected local anesthesia without sedation. The main reasons for these changes included less need for postoperative followup $(90 \%)$ and postoperative interventions $(62 \%)$, shorter surgical time (48\%) and improved safety (35\%).

There are some limitations in our study. Data obtained in the Hospital's system did not include patients' demographics, which prevented us from analyzing the influence of age, gender, residence location and previous diagnosis on our findings. However, a previous study reported that $54.8 \%$ of the patients followed at our service were male, with a mean age of 60.92 \pm 17.49 years. The most frequent diagnosis were primary openangle glaucoma $(56.2 \%)$, primary angle-closure glaucoma (20.4\%), glaucoma suspects $(12.8 \%)$, congenital and juvenile glaucoma (6.6\%), normal tension glaucoma (3.0\%) and ocular hypertension $(0.6 \%) .{ }^{34}$ Also, although we hypothesize that the decrease in the number of visits and surgeries is likely to be associated with glaucoma progression, we were not able to directly address this issue in the present study. Furthermore, the method we used to measure adherence was indirect, using the number of medications released to patients. The employment of a direct method, through a questionnaire for example, would complement the information about compliance and the reasons for not attending a visit. Finally, we did not have data on nonemergency and emergency patient visits, which would help us clarify the types of patients not seen during the pandemic.

\section{Conclusions}

The Covid-19 pandemic dramatically decreased the number of outpatient visits and surgical procedures, impacting the follow-up of glaucoma patients in our service. We encourage other health care units to verify the impact of the pandemic in their own population to better prepare for a possible overload of uncontrolled glaucoma patients in the future.

\section{Abbreviations}

SUS, Brazilian public health system; WHO, World Health Organization; IOP, intraocular pressure.

\section{Data Sharing Statement}

The datasets used and/or analyzed during the current study are available from the corresponding author upon request.

\section{Ethics Approval and Consent to Participate}

This single-center retrospective cohort study was approved by the Ethics Committee of the University of Campinas (IRB \#45206221.5.0000.5404) and conducted in compliance with the Declaration of Helsinki. The need for informed consent was waived by the Ethics Committee due to the retrospective design of the study. The patient data accessed complied with relevant data protection and privacy regulations.

\section{Acknowledgments}

We thank the Informatics Division, Surgical Center administrative coordinator and High Cost Pharmacy coordinator of Unicamp's Clinics Hospital for the support with this project.

\section{Author Contributions}

All authors made substantial contributions to conception and design, acquisition of data, or analysis and interpretation of data; took part in drafting the article or revising it 
critically for important intellectual content; agreed to submit to the current journal; gave final approval of the version to be published; and agree to be accountable for all aspects of the work.

\section{Funding}

There is no funding to report.

\section{Disclosure}

Vital P Costa: reports personal fees from Alcon, Novartis, Aerie, Eurofarma, and Glaukos and grants from Allergan, outside the submitted work; being a consultant for Alcon, Allergan, Aerie, research grants from Alcon and Zeiss, and speaker bureaus for Alcon, Novartis, Zeiss, and Iridex. The authors report no other potential conflicts of interest for this work.

\section{References}

1. Flaxman SR, Bourne RRA, Resnikoff S, et al. Global causes of blindness and distance vision impairment 1990-2020: a systematic review and meta-analysis. Lancet Glob Heal. 2017;5(12):e1221e1234. doi:10.1016/S2214-109X(17)30393-5

2. Weinreb RN, Aung T, Medeiros FA. The pathophysiology and treatment of glaucoma: a review. JAMA. 2014;311(18):1901-1911. doi:10.1001/jama.2014.3192

3. Sakata K, Sakata LM, Sakata VM, et al. Prevalence of glaucoma in a South Brazilian population: projeto glaucoma. Invest Ophthalmol Vis Sci. 2007;48(11):4974-4979. doi:10.1167/iovs.07-0342

4. World Health Organization. Novel coronavirus - China. Available from: https://www.who.int/csr/don/12-january-2020-novelcoronavirus-china/en/. Accessed March 21, 2021.

5. Zhu N, Zhang D, Wang W, et al. A novel coronavirus from patients with pneumonia in China, 2019. $N$ Engl J Med. 2020;382 (8):727-733. doi:10.1056/nejmoa2001017

6. Huang C, Wang Y, Li X, et al. Clinical features of patients infected with 2019 novel coronavirus in Wuhan, China. Lancet. 2020;395 (10223):497-506. doi:10.1016/S0140-6736(20)30183-5

7. World Health Organization. Virtual press conference on COVID-1911 March 2020. Available from: http://mpoc.org.my/malaysian-palmoil-industry/. Accessed October 26, 2021.

8. Coronavírus Brasil. Available from: https://covid.saude.gov.br/. Accessed May 6, 2021.

9. Ranzani OT, Bastos LSL, Gelli JGM, et al. Characterisation of the first 250000 hospital admissions for COVID-19 in Brazil: a retrospective analysis of nationwide data. Lancet Respir Med. 2021;9(4):407-418. doi:10.1016/S2213-2600(20)30560-9

10. COVID-19 Map - Johns Hopkins coronavirus resource center. Available from: https://coronavirus.jhu.edu/map.html. Accessed April 29, 2021.

11. Nguyen AX, Gervasio KA, Wu AY. Differences in SARS-CoV-2 recommendations from major ophthalmology societies worldwide. BMJ Open Ophthalmol. 2020;5(1):1-13. doi:10.1136/bmjophth-2020-000525

12. Recommendations for urgent and nonurgent patient care - American Academy of Ophthalmology. Available from: https://www.aao.org/ headline/new-recommendations-urgent-nonurgent-patient-care. Accessed May 12, 2021.

13. Returning to ophthalmology practice - American Academy of Ophthalmology. Available from: https://www.aao.org/about/govern ance/academy-blog/post/returning-to-ophthalmology-practice. Accessed May 12, 2021.
14. The Royal College of Ophthalmologists. Glaucoma management plans during COVID-19; 2020.

15. dell'Omo R, Filippelli M, Virgili G, et al. Effect of COVID-19related lockdown on ophthalmic practice in Italy: a report from 39 institutional centers. Eur J Ophthalmol. 2021:1-9. doi:10.1177/ 11206721211002442

16. Mishra D, Nair AG, Gandhi RA, et al. The impact of COVID-19 related lockdown on ophthalmology training programs in India outcomes of a survey. Indian J Ophthalmol. 2020;68(6):999-1004. doi:10.4103/ijo.IJO

17. Silva N, Laiginhas R, Meireles A, Barbosa Breda J. Impact of the COVID-19 pandemic on ophthalmology residency training in Portugal. Acta Med Port. 2020;33(13):1-9. doi:10.20344/AMP.14341

18. Alahmadi AS, Alhatlan HM, Bin HH, Khandekar R, Al HA, AlShahwan S. Residents' perceived impact of covid-19 on Saudi ophthalmology training programs-a survey. Clin Ophthalmol. 2020;14:3755-3761. doi:10.2147/OPTH.S283073

19. Holland LJ, Mercieca KJ, Kirwan JF. Effect of COVID-19 pandemic on glaucoma surgical practices in the UK. $\mathrm{Br} J$ Ophthalmol. 2021:1-5. doi:10.1136/bjophthalmol-2021-319062

20. Subathra G, Rajendrababu SR, Senthilkumar VA, Mani I, Udayakumar B. Impact of COVID-19 on follow-up and medication adherence in patients with glaucoma in a tertiary eye care centre in south India. Indian J Ophthalmol. 2021;69(5):1264-1270. doi:10.4 103/ijo.IJO_164_21

21. TabNet Win32 3.0: população Residente - Estimativas para o TCU São Paulo. Available from: http://tabnet.datasus.gov.br/cgi/tabcgi. exe?ibge/cnv/poptsp.def. Accessed May 12, 2021.

22. Aquino EML, Silveira IH, Pescarini JM, Aquino R, de Souza-filho JA. Social distancing measures to control the COVID-19 pandemic: potential impacts and challenges in Brazil. Cienc e Saude Coletiva. 2020;25:2423-2446. doi:10.1590/1413-81232020256.1.10502020

23. COVID-19 observatory points to the biggest health system collapse in the history of Brazil. Available from: https://portal.fiocruz.br/en/ news/covid-19-observatory-points-biggest-health-system-collapsehistory-brazil. Accessed May 13, 2021.

24. Pandemia derruba quase 30 milhões de procedimentos médicos em ambulatórios do SUS. Available from: https://portal.cfm.org.br/noti cias/pandemia-derruba-quase-30-milhoes-de-procedimentos-medicos -em-ambulatorios-do-sus/. Accessed October 5, 2021.

25. Gullo RM, Costa VP, Bernardi L, Kara-José N. Condiçöes visuais de pacientes glaucomatosos em um hospital universitário. Arq Bras Oftalmol. 1996;59(2):147-150.

26. de Oliveira A, Paranhos Júnior A, Prata Júnior JA. Characteristics presented by patients on their first appointment at the glaucoma sector of Universidade Federal de São Paulo - UNIFESP. Arq Bras Oftalmol. 2003;66(6):785-790. doi:10.1590/s0004-274920030 00700010

27. Waterman H, Evans JR, Gray TA, Henson D, Harper R. Interventions for improving adherence to ocular hypotensive therapy. Cochrane Database Syst Rev. 2013;2013(4). doi:10.1002/14651858.CD0 06132.pub3

28. Silva LM, de Vasconcellos JP, Temporini ER, et al. Clinical glaucoma treatment at a university hospital: monthly cost and financial impact. Arq Bras Oftalmol. 2002;65(3):299-303. doi:10.1590/s0004-27492 002000300003

29. The AGIS Investigators. The Advanced Glaucoma Intervention Study (AGIS): 7. The relationship between control of intraocular pressure and visual field deterioration. Am $J$ Ophthalmol. 2000;130 (4):429-440. doi:10.1016/S0002-9394(00)00538-9

30. GDP drops $4.1 \%$ in 2020 and closes the year at R\$ 7.4 trillion. Agência de Notícias, IBGE. Available from: https://agenciadenoti cias.ibge.gov.br/en/agencia-press-room/2185-news-agency/releasesen/30169-pib-cai-4-1-em-2020-e-fecha-o-ano-em-r-7-4-trilhoes-2. Accessed May 12, 2021. 
31. TabNet Win32 3.0: 47b - Estimativa da população SUS dependente (com base na Saúde Suplementar). Available from: http://tabnet saude.Sp.gov.br/tabcgi.exe?tabnet/ind47b_matriz.def. Accessed May 12, 2021.

32. Dmuchowska DA, Pieklarz B, Konopinska J, Mariak Z, Obuchowska I. Impact of three waves of the covid-19 pandemic on the rate of elective cataract surgeries at a tertiary referral center: a Polish perspective. Int J Environ Res Public Health. 2021;18 (16):1-8. doi:10.3390/ijerph18168608
33. Dmuchowska D, Cwalina I, Krasnicki P, et al. The impact of three waves of the COVID-19 pandemic on the characteristics of primary rhegmatogenous retinal detachments at a tertiary referral centre. Clin Ophthalmol. 2021;15:3481-3491. doi:10.2147/opth.s323998

34. Urbano AP, Freitas TG, Arcieri ES, Urbano AP, Costa VP. Evaluation of glaucoma types at the sector of ophthalmology-UNICAMP. Arq Bras Oftalmol. 2003;66(2):61-65. doi:10.1590/S0004-2749200 3000100012

\section{Publish your work in this journal}

Clinical Ophthalmology is an international, peer-reviewed journal covering all subspecialties within ophthalmology. Key topics include: Optometry; Visual science; Pharmacology and drug therapy in eye diseases; Basic Sciences; Primary and Secondary eye care; Patient Safety and Quality of Care Improvements. This journal is indexed on PubMed

Submit your manuscript here: https://www.dovepress.com/clinical-ophthalmology-journal
Central and CAS, and is the official journal of The Society of Clinical Ophthalmology (SCO). The manuscript management system is completely online and includes a very quick and fair peer-review system, which is all easy to use. Visit http://www.dovepress.com/ testimonials.php to read real quotes from published authors. 